\title{
Ammonia Sensors Based on Composites of Carbon Nanotubes and Titanium Dioxide
}

\author{
Marciano Sánchez and Marina Rincón \\ Centro de Investigación en Energía, Universidad Nacional Autónoma de México \\ México
}

\section{Introduction}

Design of composite materials for ammonia $\left(\mathrm{NH}_{3}\right)$ sensing is important because of two main reasons: (1) $\mathrm{NH}_{3}$ is the most common substitute for chlorofluorocarbons (CFCs) in cooling systems, and (2) most sensors show long recovery times at room temperature due to the tendency of ammonia to strongly interact with many substrates. Multiwalled carbon nanotubes (MWCNTs) have been used to sense polar molecules like carbon monoxide (CO), carbon dioxide $\left(\mathrm{CO}_{2}\right), \mathrm{NH}_{3}$, water $\left(\mathrm{H}_{2} \mathrm{O}\right)$, and ethanol $\left(\mathrm{C}_{2} \mathrm{H}_{5} \mathrm{OH}\right)$ (Ong et al., 2002; Valentini et al., 2004; Varghese et al., 2001), as well as non polar gases like helium (He) and nitrogen $\left(\mathrm{N}_{2}\right)$ (Adu et al., 2001). For carbon nanotubes, studies have shown that $\mathrm{O}_{2}$ molecules are electron acceptors with substantial adsorption energies and charge transference, while $\mathrm{NH}_{3}$, $\mathrm{N}_{2}, \mathrm{CO}_{2}$, methane $\left(\mathrm{CH}_{4}\right), \mathrm{H}_{2} \mathrm{O}$, hydrogen $\left(\mathrm{H}_{2}\right)$ and argon (Ar) are electron donors (Zhao et al., 2002). Adsorption in CNTs is determined by adsorption energy and availability of sites, with typically four different adsorption sites: external surface, grooves between CNTs on the bundle outside, pores inside CNTs, and interstitial channel between adjacent tubes inside the bundle (Stan \& Cole, 1998; Williams \& Eklund, 2000). Additionally, theoretical studies carried out by Jhi et al. about the electronic and magnetic properties of oxidized CNTs indicated their high potential as gas sensors. These studies demonstrated that the sensing mechanism of as prepared CNTs is more related to oxygen doping than to intrinsic properties, and depends on the structural defects caused by the synthesis methods (Jhi et al., 2000).

With the aim of increasing the response of CNTs to certain gases, some studies about substitutional functionalization of CNTs have been reported (Peng \& Cho, 2003). Although boron (B) and nitrogen (N) doping improve the response to gases like $\mathrm{CO}$ and $\mathrm{H}_{2} \mathrm{O}, \mathrm{B}_{\mathrm{x}} \mathrm{C}_{\mathrm{y}}$ nanotubes show stronger chemisorption, in contrast with the substitutional functionalization with nitrogen (Villalpando-Paez et al., 2004). Oxidation of CNTs in acid solutions to graft oxygen functional groups [i.e., carboxyl $(\mathrm{COOH})$, hydroxyl $(\mathrm{OH})$, and carbonyl (CO)] on CNT walls have been widely used to diversify the sensing options. Another strategy has been the fabrication of compound materials based on CNTs and metallic oxides. Espinoza et al. reported the use of metallic oxides-CNT composites based on commercial tin $\left(\mathrm{SnO}_{2}\right)$ and tungsten $\left(\mathrm{WO}_{3}\right)$ oxide powders, as well as sol gel $\mathrm{TiO}_{2}$ materials, in the sensing of $\mathrm{NO}_{2}$ and $\mathrm{CO}$ at room temperature and $150^{\circ} \mathrm{C}$. Their results indicated a better performance for $\mathrm{CNT} / \mathrm{SnO}_{2}$ and $\mathrm{CNT} / \mathrm{WO}_{3}$ than for $\mathrm{CNT} / \mathrm{TiO}_{2}$, for the titania composite the sensor response was barely sizable (Espinoza et al., 2007). 
Throughout this chapter, we will present the synthesis and performance of compound materials based on $\mathrm{MWCNT} / \mathrm{TiO}_{2}$ tested as resistor and capacitor ammonia sensors. The design aims for low cost room temperature sensors with good reversibility and fast recovery times. For sensor fabrication, both materials were prepared separately (ex-situ) and deposited in a multilayer configuration. By means of spacial and spectroscopic resolution techniques we were able to correlate sensor fabrication with performance. We will demonstrate that the ex situ method combined with substantial chemical oxidation of pretreated CNTs provide the best composite material with synergistic properties for ammonia sensing. Variations of capacitance were as high as $150 \%$, while changes in resistance were one order of magnitude lower.

\section{Experimental}

\subsection{Film elaboration techniques MWCNT functionalization}

MWCNTs were obtained from Nanostructured \& Amorphous Materials Inc. (90 wt.\%, outer diameter $<10 \mathrm{~nm}$, length: 5-15 $\mu \mathrm{m}$, tangled). To introduce oxigenated functional groups, CNTs were refluxed at $100^{\circ} \mathrm{C}$ for $6 \mathrm{~h}$ in acid solutions of $0.5 \mathrm{M}$ sulphuric acid $\left(\mathrm{H}_{2} \mathrm{SO}_{4}\right)$ with variable concentrations of nitric acid $\left(\mathrm{HNO}_{3}\right)$. Functionalized $\mathrm{CNTs}$ were labelled according to the concentration of $\mathrm{HNO}_{3}(2.5 \mathrm{M}, 7.5 \mathrm{M}, 12.5 \mathrm{M})$ as CNT-2.5, CNT-7.5 and CNT-12.5, CNTs without treatment were labeled as CNT-WT, composites were labeled as CMP with the number of the $\mathrm{HNO}_{3}$ concentration used for chemical treatment. CNT inks were prepared mixing $10 \mathrm{mg}$ of CNTs with $40 \mu \mathrm{L}$ of triton X-100 in $5 \mathrm{~mL}$ of deionized water, the triton/CNT weight ratio was 0.6.

\section{Sensor fabrication (ex-situ method)}

To prepare $\mathrm{TiO}_{2}$ films, $100 \mathrm{~mL}$ sol gel baths containing $92 \mathrm{~mL}$ of isopropanol, $0.1 \mathrm{~mL}$ of hydrochloric acid $(\mathrm{HCl})$, and $8 \mathrm{~mL}$ of titanium isopropoxide were kept at room temperature $\left(27^{\circ} \mathrm{C}\right)$ for $24-48 \mathrm{~h}$. Films were deposited by dip coating on glass (Corning) and indium tin oxide (ITO) $1 \times 1.5$ in substrates, using 8 dipping/withdrawing cycles at $30 \mathrm{~mm} / \mathrm{min}$ speed, and air annealing for $5 \mathrm{~min}$ at $400^{\circ} \mathrm{C}$ after each immersion, and at $500^{\circ} \mathrm{C}$ for $1 \mathrm{~h}$ after the last cycle. After $\mathrm{TiO}_{2}$ deposition, $0.5 \mathrm{~mL}$ of $\mathrm{CNT}$ ink was drop casted on top and was dried at room temperature for $24 \mathrm{~h}$. The two layer film was annealed in air for $30 \mathrm{~min}$ at $400^{\circ} \mathrm{C}$, finally another $\mathrm{TiO}_{2}$ film (8 cycles) were deposited to make a sandwich like configuration; the whole system was annealed at $400^{\circ} \mathrm{C}$ in air for $1 \mathrm{~h}$.

\subsection{Characterization}

The changes in chemical composition caused by the functionalization of CNTs were followed by thermogravimetric analysis (TGA, TA Instruments Q500). TGA studies were carried out under $5 \mathrm{~mL} / \mathrm{min}$ oxygen flow and using $5^{\circ} \mathrm{C} / \mathrm{min}$ heating rate in the $25-800^{\circ} \mathrm{C}$ temperature range. Particle size and zeta potential $(\zeta)$ were measured by dynamic light scattering (DLS, Zetasizer Nano, Malvern Instruments) as a function of CNTs functionalization. Film crystallinity was monitored by X-ray diffraction (Rigaku Dmax 2200, CuKa radiation, $\lambda=1.5405 \AA$ ), using the Debye-Scherer equation (Cullity, 1978) for crystallite size determination. Atomic force microscopy was used for surface microstructural studies (Nanosurf Easyscan, Nanosurf AG, Switzerland). The experimental setup for sensing trials for both platforms is shown in Figure 1, basically, nitrogen was passed through a bubbler 
containing ammonia and was injected into a flask where the resistance or capacitance of the sensors changed as they were exposed to ammonia; the baseline was measured in dry air and the sensor in the picture correspond to a resistor sensor.

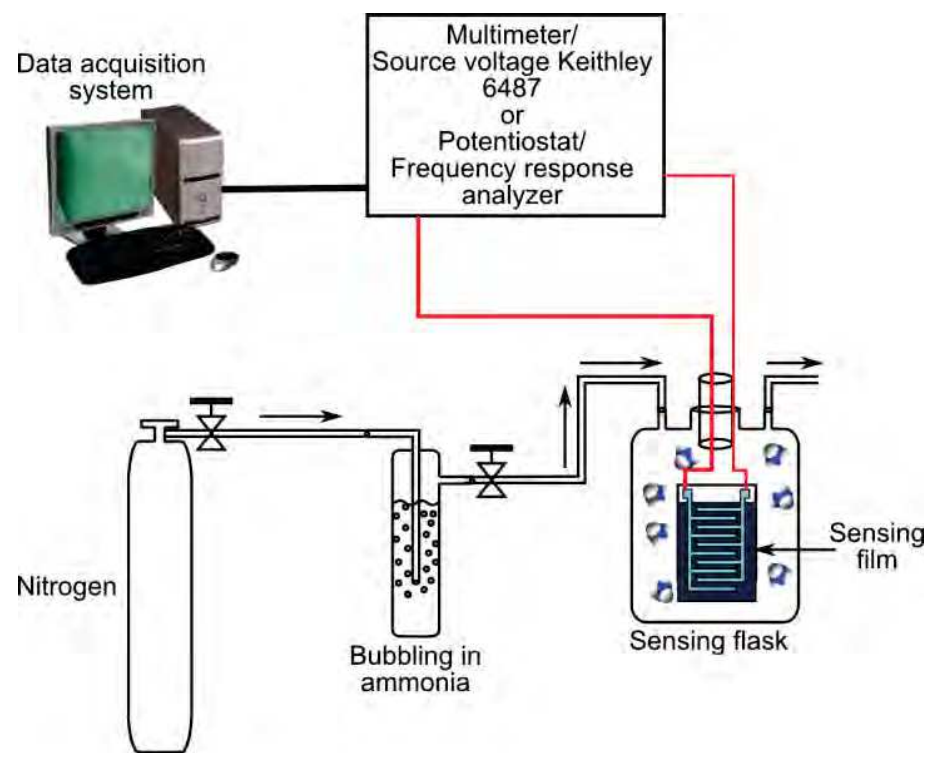

Fig. 1. Experimental setup used for sensing trials

For capacitor sensors, variations of capacitance were followed by electrochemical impedance spectroscopy (EIS) measurements in an Autolab PGSTAT302N potentiostat/galvanostat unit (Eco Chemie), using the configuration depicted in Figure 2. A perturbation of 5-10 mV was applied at open circuit potential in the frequency range from $10^{5}$ to $10^{-3} \mathrm{~Hz}$. Complex non linear least squares (CNLS) fitting of the experimental data was done with the Zsimpwin software (Princeton Applied Research). All the sensing trials were done at room temperature $\left(27^{\circ} \mathrm{C}\right)$.
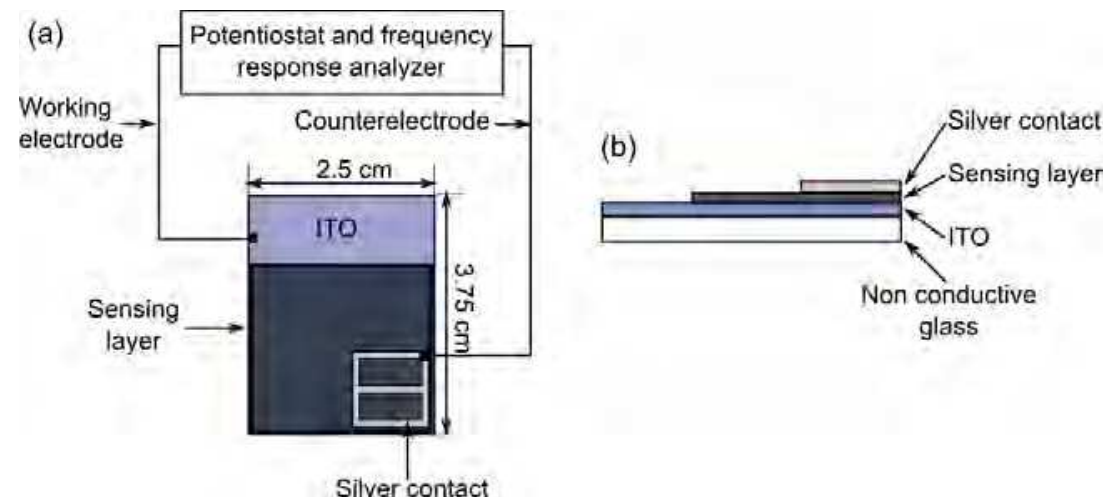

Fig. 2. Capacitor sensor configuration: (a) top view; (b) side view 


\section{Results and discussion}

\subsection{CNT characterization}

Figure 3 shows the TGA curves of CNTs exposed to various acid treatments. From the variation of mass vs. temperature [Figure 3(a)], or mass/temperature ratio vs. temperature [Figure 3(b)] figures it is easy to appreciate the $\sim 15 \mathrm{wt} . \%$ of metal and impurities content of as received CNTs (CNT-WT) as well as its removal by all the acid treatments. The higher oxidation temperature indicates that the treatment used for CNT-2.5 does not damage the nanotube surface, but as the aggressiveness of the functionalization increases, a sizable weakening of the CNT structures is observed, in addition to the grafting of oxygenated functional groups, as evidenced in Fourier transform infrared studies (Sánchez \& Rincón, 2009). DLS characterization of CNT aqueous inks prepared with a triton/CNT ratio of 0.6 and sonicated for 30 and $90 \mathrm{~min}$ is presented in Figure 4. Ultrasonic treatments of $90 \mathrm{~min}$ produced a better dispersion, especially for CNT-WT and CNT-2.5, however, for CNT-7.5 and CNT-12.5 the differences between 30 and 90 min sonication times are smaller [Figure 4(a)]. The absolute value of $\zeta$ [Figure 4(b)] shows a continuous increase as the intensity of the chemical treatment does, up to $\sim 18 \mathrm{mV}$, which is lower than the characteristic values of stable solutions $( \pm 30 \mathrm{mV})$, this increase confirms the presence of functional groups, however in the long term these solutions would show a tendency to precipitate.
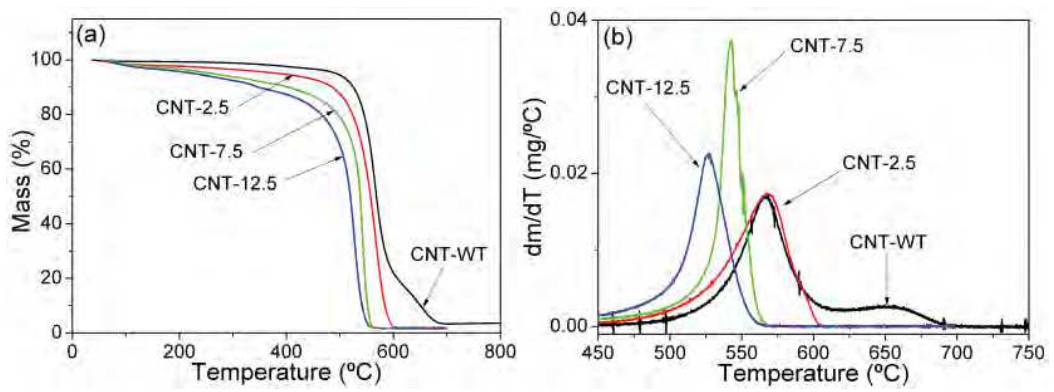

Fig. 3. Thermogravimetric analysis of CNTs in a $5 \mathrm{~mL} / \mathrm{min}$ oxygen flow and heating ratio of $5^{\circ} \mathrm{C} / \mathrm{min}$ : (a) mass vs. temperature; (b) mass/temperature ratio vs. temperature
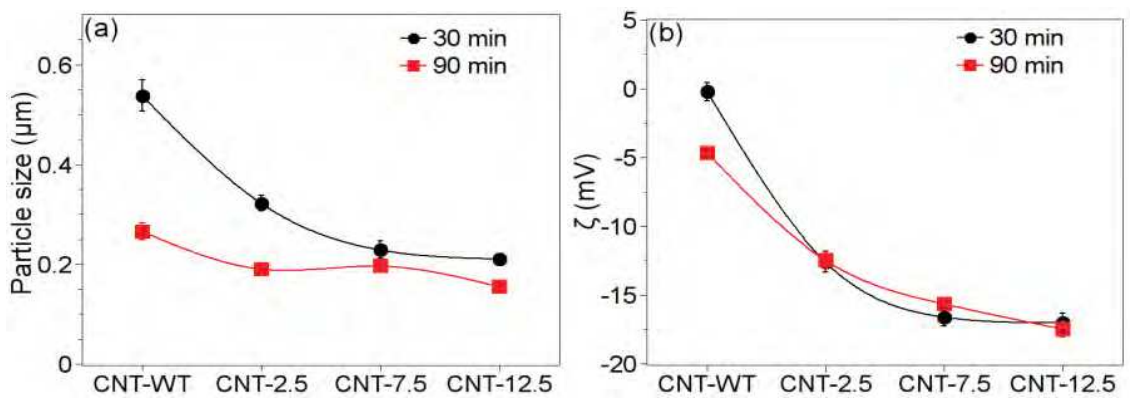

Fig. 4. Dynamic light scattering characterization of $\mathrm{CNT}$ inks based on sonication time and functionalization intensity: (a) particle size vs CNT functionalization; (b) $\zeta$ potential vs. CNT functionalization 


\subsection{Structural characterization}

The effect of CNT functionalization on the topography of the composite is shown in Figure 5. Figures $5(a-b)$ show the surface and edge detection of CMP-WT composite. Several longitudinal and tangled formations of CNTs bundled in ropes are evident. In contrast, Figures 5(c-d) show images of CMP-12.5 composite, where CNT/titania grains are slightly smaller, more dispersed, and with shorter ropes. Analysis at a lower scale (not shown) confirmed that a compact and thin layer $(\sim 20 \mathrm{~nm})$ of titania was formed covering all the surface including carbon nanotubes, with an increasing thickness as the intensity of chemical treatment does.

(a)

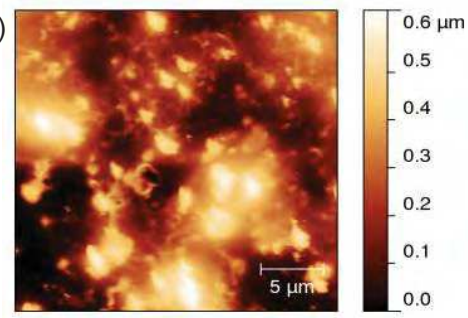

(c)

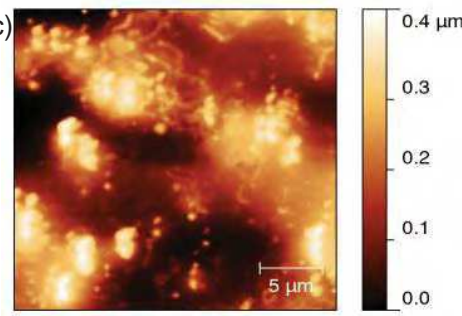

(b)

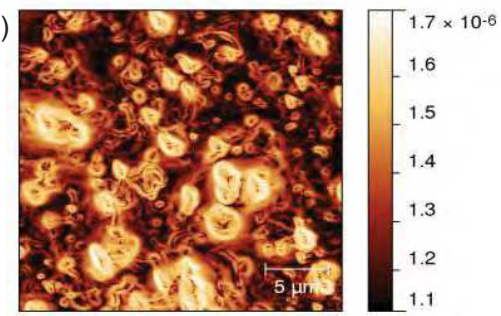

(d)

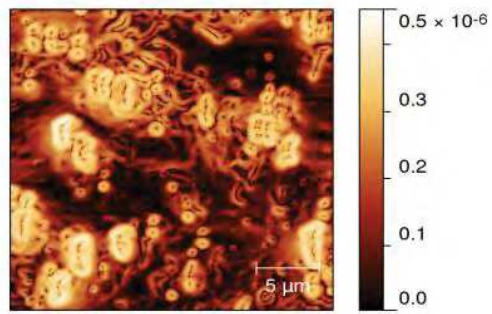

Fig. 5. AFM studies of $\mathrm{TiO}_{2} / \mathrm{CNT} / \mathrm{TiO}_{2}$ composites deposited on glass substrates: (a) topography of CMP-WT; (b) edge detection on Fig. (a) showing CNT ropes; (c) topography of CMP-12.5; (d) edge detection on Fig. (c)

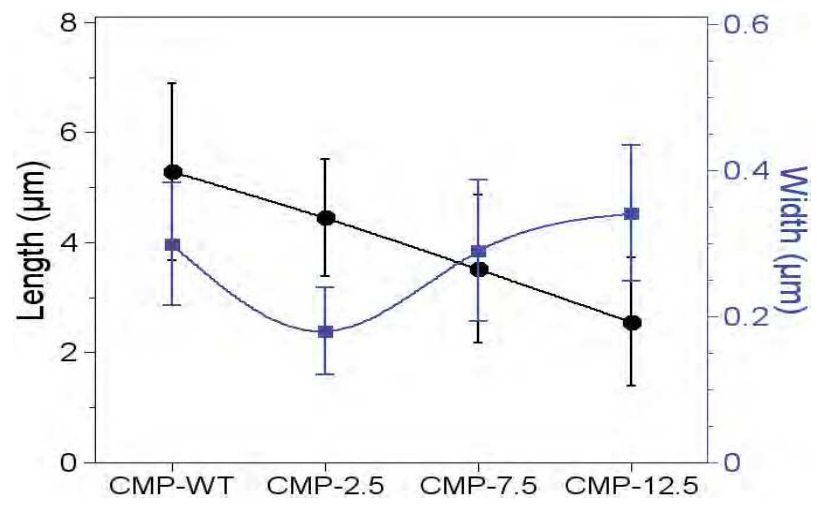

Fig. 6. Length and width of $\mathrm{CNT}$ ropes of $\mathrm{TiO}_{2} / \mathrm{CNT} / \mathrm{TiO}_{2}$ composites deposited on glass substrates 
Statistical analysis of the length and width of $\mathrm{CNT}$ ropes in $\mathrm{TiO}_{2} / \mathrm{CNT}$ composites deposited on insulator glass substrates is shown in Figure 6. This graph confirms that the chemical treatment reduces the length of ropes from $\sim 5 \mu \mathrm{m}$ for CMP-WT to $\sim 2.5 \mu \mathrm{m}$ for CMP-12.5. A slight increase in the width is observed as the intensity of functionalization increases, which can only be due to a thicker titania layer, given that thinner CNT ropes are obtained at stronger functionalizations.

X-ray diffraction studies (Figure 7) of films prepared in a multilayer configuration (system $\mathrm{TiO}_{2} / \mathrm{CNT} / \mathrm{TiO}_{2}$ ) shows only the anatase phase and broadening of its peaks. Crystallite size determination using the peak at $2 \theta \approx 48^{\circ}$ (to avoid interference from carbon diffraction at $2 \theta=25^{\circ}$ ) shows a decrease from $\sim 25 \mathrm{~nm}$ for CMP-WT to $\sim 10 \mathrm{~nm}$ for CMP12.5 (a reduction of $\sim 60 \%$ ), according to some studies that report the confined growing of titania grains attached to functionalized CNTs which are smaller than the ones growing away from nanotubes (An et al., 2007; Hieu et al., 2008; Song et al., 2007; Yu et al., 2007). This figure also confirms that CNTs with more functional groups are covered with a thicker titania layer.

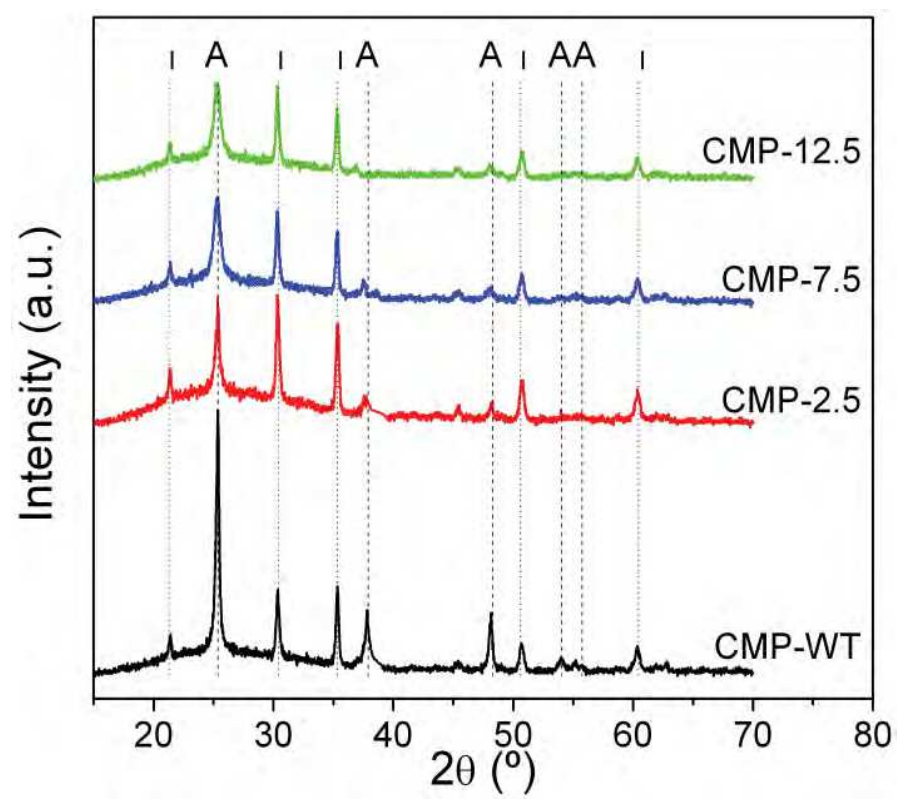

Fig. 7. X-ray diffraction patterns of multilayer systems $\mathrm{TiO}_{2} / \mathrm{CNT} / \mathrm{TiO}_{2}$ deposited on ITO substrates. A: anatase; I: ITO.

\subsection{Electrical characterization}

\subsubsection{Resistor sensors}

In this section the performance of CNTs and $\mathrm{TiO}_{2} / \mathrm{CNT}$ films as resistor ammonia sensors is presented. Figures 8-10 compare the effect of CNT functionalization on the dynamical response to 1 vol.\% ammonia of CNT (Figure 8), $\mathrm{CNT} / \mathrm{TiO}_{2}$ (Figure 9), and $\mathrm{TiO}_{2} / \mathrm{CNT} / \mathrm{TiO}_{2}$ (Fig. 10). Some of these figures show passivation of the most reactive sites during the first pulse, and reversible responses in the subsequent pulses. 

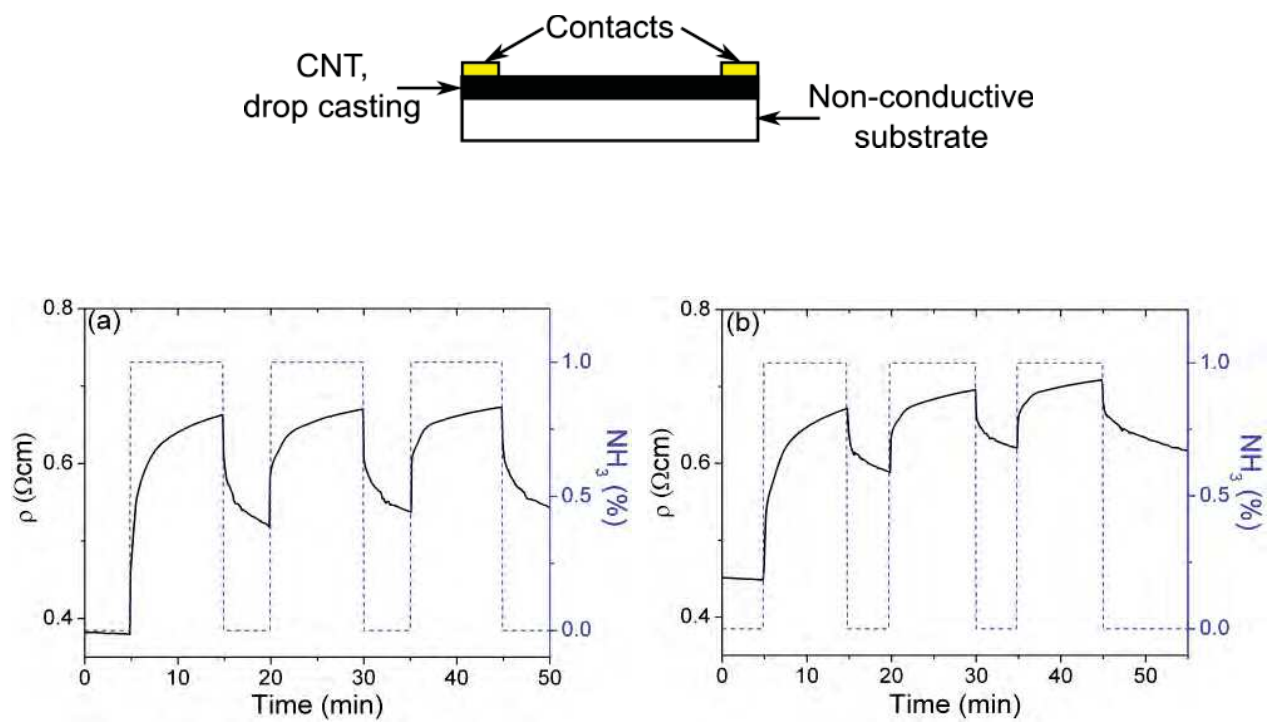

Fig. 8. Dynamical reponse to ammonia of CNT resistor films deposited by drop casting: (a) CNT-WT; (b) CNT-2.5
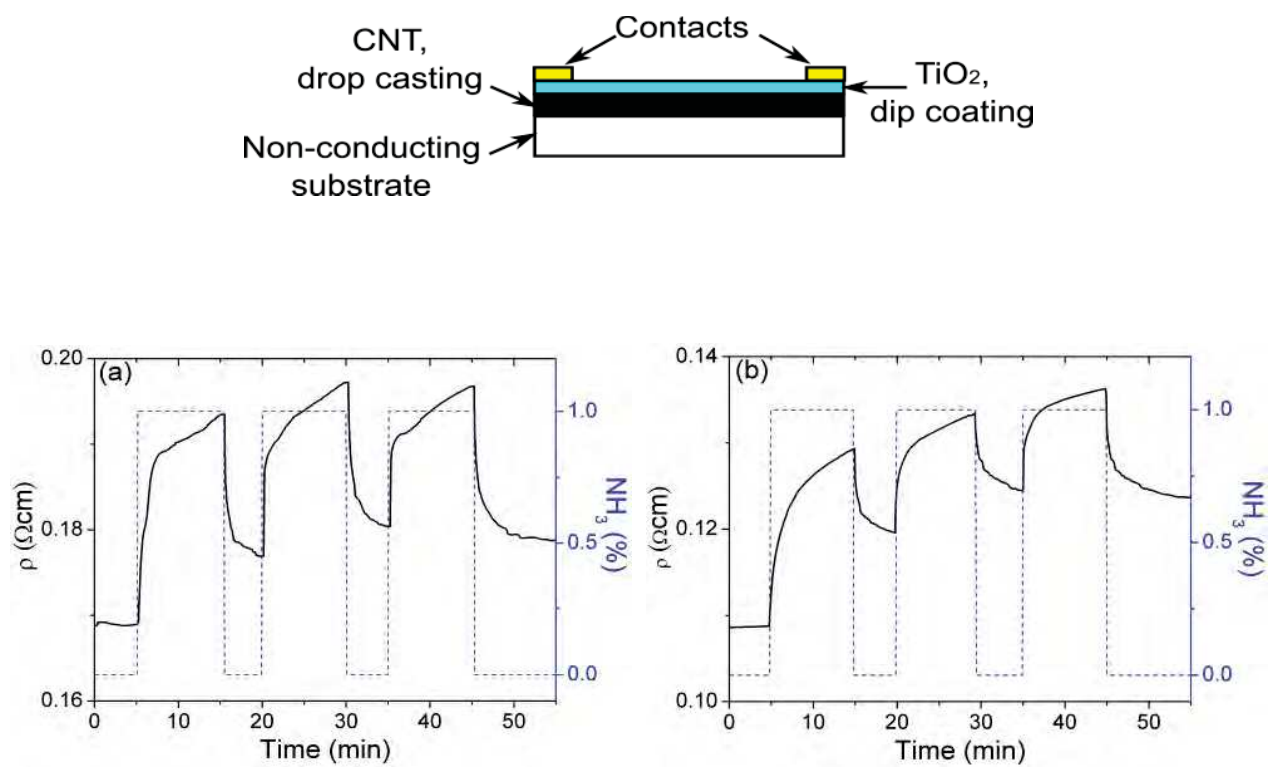

Fig. 9. Dynamical response to ammonia of compound films of CNTs (drop casting) and $\mathrm{TiO}_{2}$ (dip coating): (a) $\mathrm{CNT}-\mathrm{WT} / \mathrm{TiO}_{2}$; (b) $\mathrm{CNT}-2.5 / \mathrm{TiO}_{2}$ 

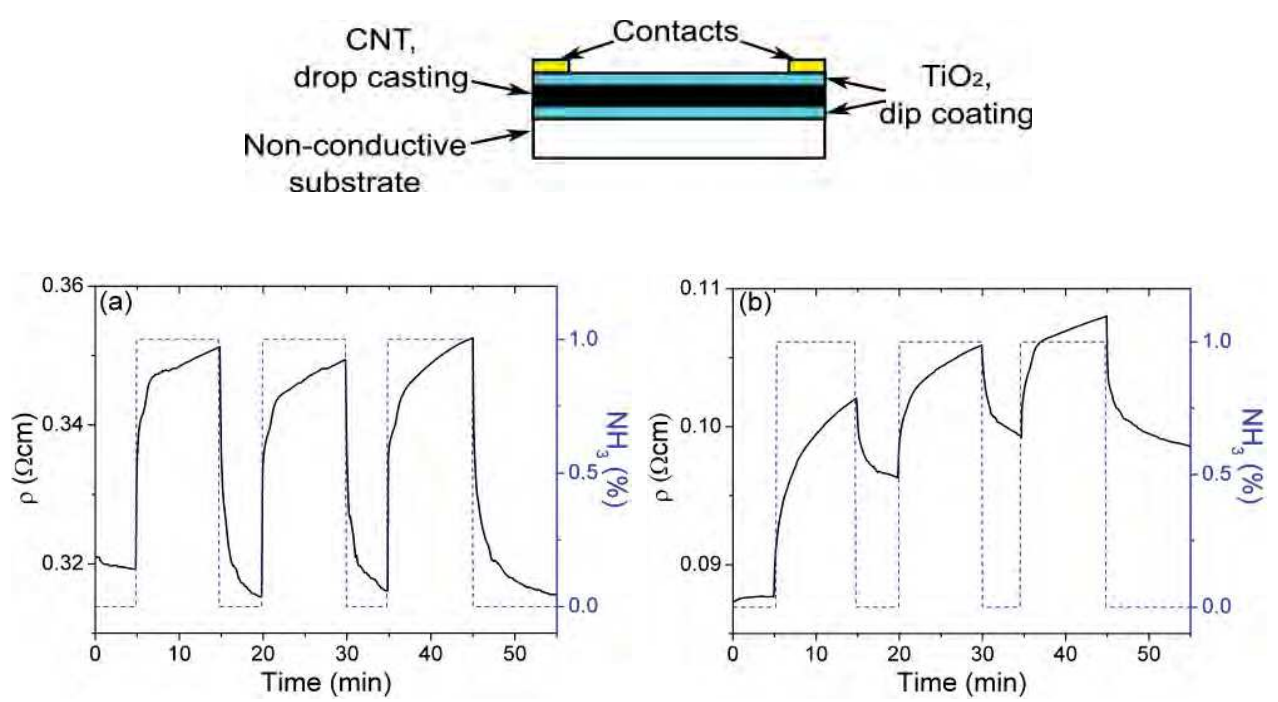

Fig. 10. Dynamical response to ammonia of compound films of CNTs (drop casting) and $\mathrm{TiO}_{2}$ (dip coating): (a) $\mathrm{TiO}_{2} / \mathrm{CNT}-\mathrm{WT} / \mathrm{TiO}_{2}$; (b) $\mathrm{TiO}_{2} / \mathrm{CNT}-2.5 / \mathrm{TiO}_{2}$

To quantify the effect of the inclusion of titania layers and the use of functionalized CNTs Figure 11 shows the comparison of the resistivity in air, the sensor response $\left(S_{R}\right)$ (equation 3 ), the adsorption and desorption times, and the reversibility (equation 4).

$$
\begin{gathered}
S_{R}=R_{\text {ammonia }} / R_{\text {air }} \\
R=\Delta R_{\text {desorption }} / \Delta R_{\text {adsorption }}
\end{gathered}
$$

The resistivity in air [Figure $11(\mathrm{a})$ ] shows a decrease up to $\sim 80 \%$ when CNTs are covered with titanium dioxide, affecting also the value of $S$. In titania-free materials, the effect of functionalization is to increase the resistivity in air, while in those containing titania the resistivity decreases and this drop is more notorious in sensors with a higher number of titania layers. With respect to the adsorption/desorption times a clear reduction is observed in the time required for adsorption in functionalized materials, whereas the effect of titania layers is difficult to appreciate. For desorption times, the presence of $\mathrm{TiO}_{2}$ layers causes up to one order decrease $(\sim 90 \%)$ and it is far more important than CNT functionalization. The faster sensors correspond to a combination of functionalized CNTs and the presence of $\mathrm{TiO}_{2}$ layers, see systems CNT-2.5/ $\mathrm{TiO}_{2}$ and $\mathrm{TiO}_{2} / \mathrm{CNT}-2.5 / \mathrm{TiO}_{2}$.

Some observations from AFM studies can help to explain the electrical behavior of these composites. Dip coating is a technique that applies strong pressures on the surface as films are deposited (Brinker \& Hurd, 1994), therefore it results in the deposition of compact and continuous titania films as was observed by AFM and aids to the formation of new paths for charge carriers. These processes are enhanced if functionalized CNTs are used, giving composites with lower resistivity. There are also some studies that report a larger work function for the $\mathrm{TiO}_{2}$ than for CNT (Ou et al., 2006; Wang et al., 2005), opening the posibillity for electronic transfer from $\mathrm{CNT}$ to $\mathrm{TiO}_{2}$ (Figure 12), increasing the composite conductivity through the increase of titania conductivity and dedoping of CNTs. 

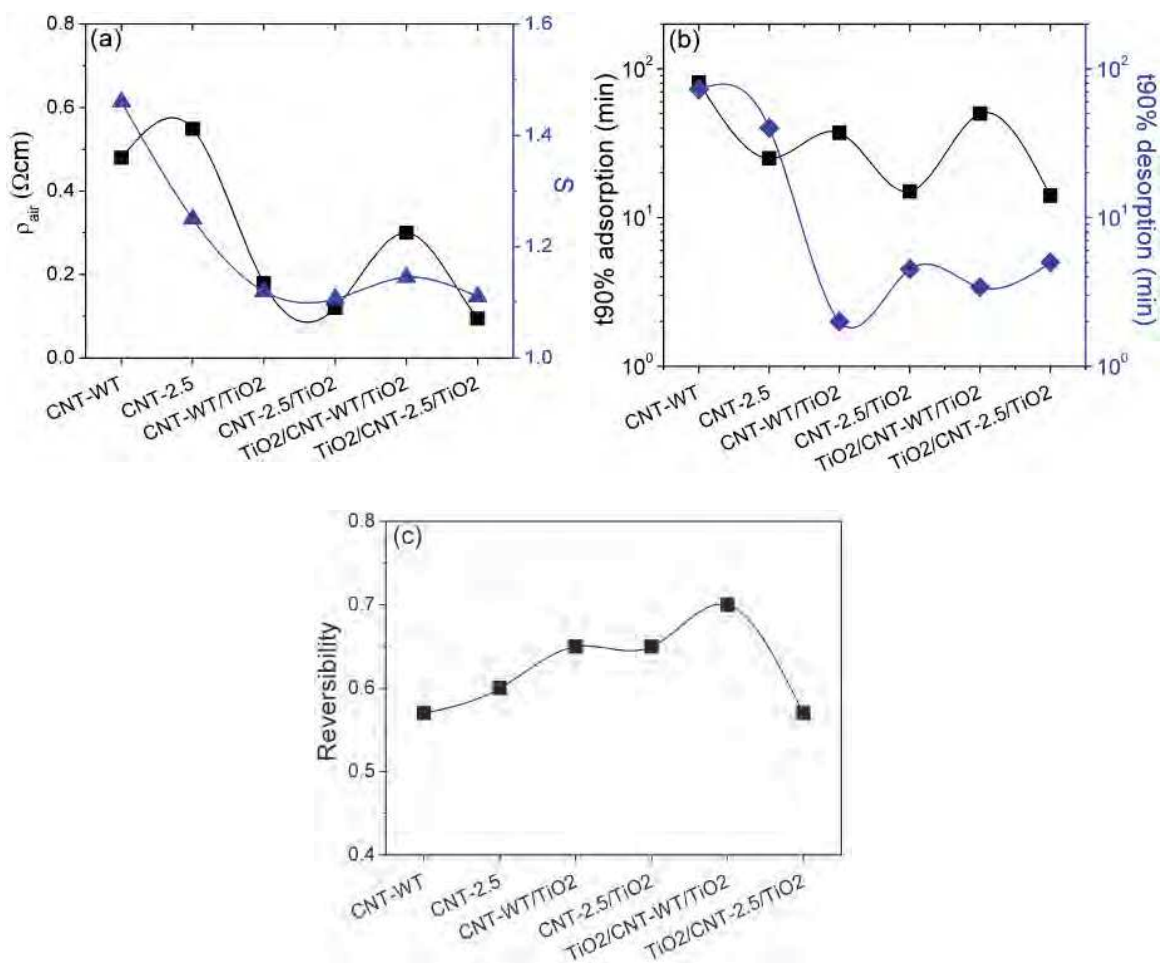

Fig. 11. Characterization of single and multilayer films: (a) resistivity in air and sensor response; (b) adsorption and desorption times; (c) reversibility

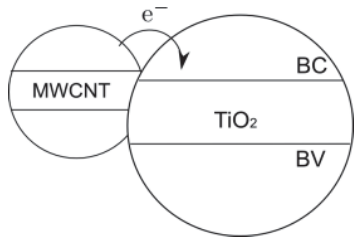

Fig. 12. Electronic transference from MWCNTs to the conduction band of $\mathrm{TiO}_{2}$

\subsubsection{Capacitor sensors}

EIS studies of multilayer systems $\mathrm{TiO}_{2} / \mathrm{CNT}-\mathrm{X} / \mathrm{TiO}_{2}$ prepared by dip coating and drop casting using CNT-WT and CNT-2.5 are presented in Figures 13 and 14, respectively. Cole-Cole plots are shown in Figures 13(a) and 14(a), the variations of phase angle vs frequency are shown in Figures 13(b) and 14(b), and the results of fitting experimental data with equivalent circuits are presented in Tables 1 and 2. The equivalent circuit used to fit the experimental data of $\mathrm{TiO}_{2} / \mathrm{CNT}-\mathrm{WT} / \mathrm{TiO}_{2}$ composite [Figure 13(a)] consists of a resistance $\mathrm{R}_{0}$ in series with three subcircuits: higher frequencies $\left(R_{1} C_{1}\right)$, intermediate frequencies $\left(R_{2} Q_{2}\right)$, and lower frequencies $\left(\mathrm{R}_{3} \mathrm{C}_{3}\right)$. The value of $\mathrm{R}_{1}$ (few ohms) decreases as the material is exposed to ammonia, in contrast to the values of $R_{2}$ and of $R_{3}$ (several kohms) which show an increase. Capacitance values do 
not show a unique tendency either, $C_{1}$ increases, $C_{2}$ it is almost constant, and $C_{3}$ decreases with ammonia exposure. Differences among capacitances values are of several orders of magnitude suggesting that adsorption processes are taking place in different sites.
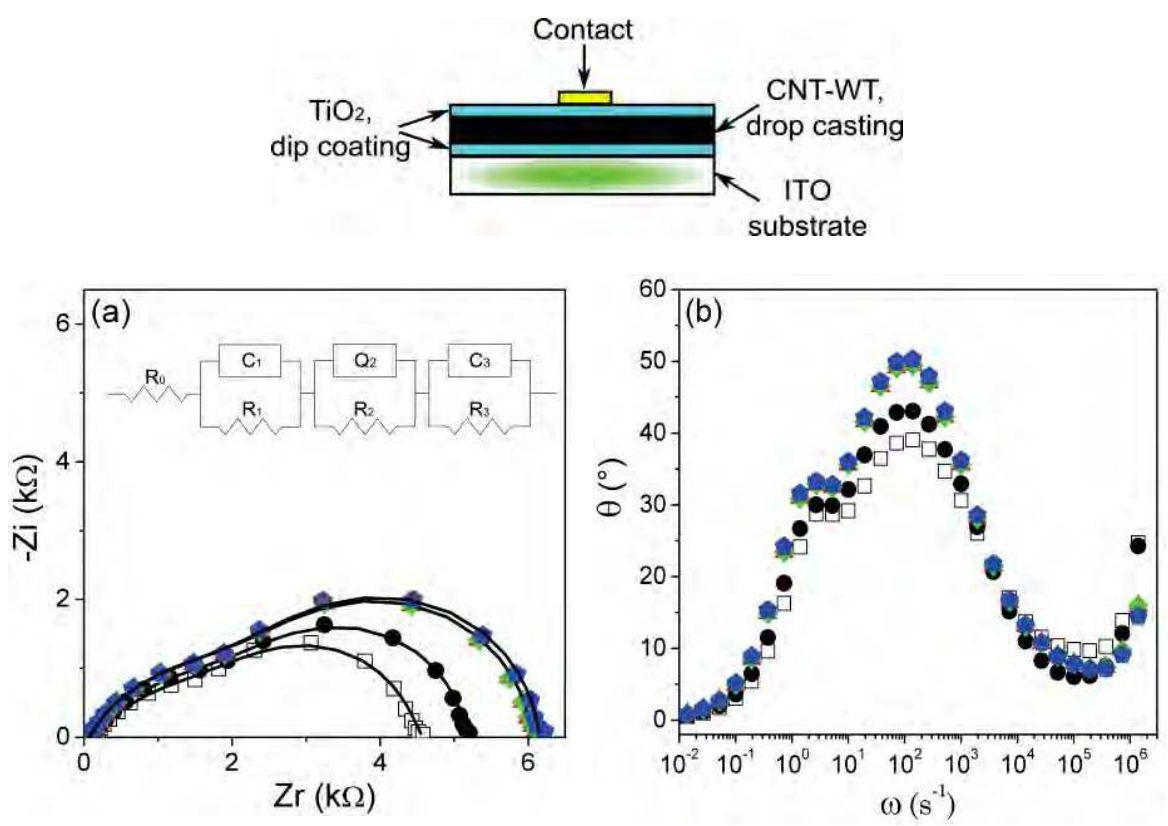

Fig. 13. EIS studies of the composite $\mathrm{TiO}_{2} / \mathrm{CNT}-\mathrm{WT} / \mathrm{TiO}_{2}$ with $\mathrm{CNT}$ s deposited by drop casting and $\mathrm{TiO}_{2}$ layers prepared by dip coating: (a) Cole-Cole plot; (b) phase angle vs angular frequency. Colors code: white square: air; black circle: $\mathrm{NH}_{3} 1$ vol.\%; red triangle: $\mathrm{NH}_{3} 4$ vol.\%, 5 min; green diamond: $\mathrm{NH}_{3} 4$ vol.\%, 10 min; blue pentagon: $\mathrm{NH}_{3} 4$ vol.\%, 15 min. Markers are experimental data and lines are the fitting results.

In contrast to the multilayer sensor based on non-functionalized CNTs, EIS results of $\mathrm{TiO}_{2} / \mathrm{CNT}-2.5 / \mathrm{TiO}_{2}$ required only two subcircuits to fit the experimental data depicted in Figure 14 . The subcircuit at higher $\left(R_{1} C_{1}\right)$ and lower $\left(R_{2} Q_{2}\right)$ frequencies are evident in air, but during ammonia exposure only the process at lower frequencies dominates. $R_{1}$ values have been related to $\mathrm{TiO}_{2}$ grain boundaries in $\mathrm{TiO}_{2}-\mathrm{CNT}$ composites, although the value of $\sim 10^{1} \Omega$ is lower than the typical values $\left(\sim 10^{3} \Omega\right)$ (Sánchez et al., 2009), this difference could be related to processes taking place at the $\mathrm{CNT} / \mathrm{TiO}_{2}$ interface, supporting the improved connectivity of the materials and the direction of charge transfer from $\mathrm{CNT}=>\mathrm{TiO}_{2}$. With respect to the subcircuits at intermediate and lower frequencies in composites based on CNT-WT, changes in capacitances and resistances when the films are exposed to ammonia suggest the presence of two carbon types or two different adsorption sites. In contrast, for composites based on CNT-2.5, amorphous carbon and metal catalysts are removed during functionalization, defining the surface of CNTs as the main adsorption site. Reduction of $\mathrm{R}_{2}$ in air as well as in ammonia, suggest doping of both $\mathrm{TiO}_{2}$ and CNTs, because the electronic transference from CNTs to $\mathrm{TiO}_{2}$ might be facilitated by the formation of covalent bonds during functionalization. Given the tendencies described, we propose that subcircuit 1 is the 


\begin{tabular}{|c|c|c|c|c|c|}
\hline Element & Air & $1 \%, 5 \mathrm{~min}$ & $4 \%, 5$ min & $4 \%, 10 \mathrm{~min}$ & $4 \%, 15 \mathrm{~min}$ \\
\hline $\mathrm{R}_{0}(\Omega)$ & 51 & 46 & 46 & 46 & 46 \\
\hline $\mathrm{R}_{1}(\Omega)$ & 53 & 56 & 37 & 26 & 23 \\
\hline $\mathrm{C}_{1}(\mathrm{nF})$ & 3.1 & 2.1 & 4.3 & 8.3 & 11.0 \\
\hline$\tau_{1}(\mu \mathrm{s})$ & 0.16 & 0.11 & 0.16 & 0.21 & 0.25 \\
\hline$\omega_{1}\left(\mathrm{~s}^{-1}\right) \times 10^{6}$ & 6.08 & 8.5 & 6.3 & 4.6 & 3.9 \\
\hline $\mathrm{R}_{2}(\mathrm{k} \Omega)$ & 2.78 & 2.7 & 2.9 & 2.8 & 2.8 \\
\hline $\mathrm{Q}_{2}{ }^{0}\left(\mu \mathrm{Ss}^{\mathrm{n} 2}\right)$ & 35 & 24 & 23 & 22 & 22 \\
\hline $\mathrm{n}_{2}$ & 0.57 & 0.6 & 0.7 & 0.7 & 0.7 \\
\hline $\mathrm{C}_{2}(\mu \mathrm{F})$ & 6.0 & 5.1 & 5.6 & 5.9 & 6.2 \\
\hline $\mathrm{T}_{2}(\mathrm{~ms})$ & 17 & 14 & 16 & 17 & 18 \\
\hline$\omega_{2}\left(\mathrm{~s}^{-1}\right)$ & 60 & 72 & 62 & 60 & 57 \\
\hline $\mathrm{R}_{3}(\mathrm{k} \Omega)$ & 1.7 & 2.4 & 2.9 & 3.1 & 3.3 \\
\hline $\mathrm{C}_{3}(\mu \mathrm{F})$ & 75 & 65 & 64 & 64 & 62 \\
\hline$\tau_{3}(s)$ & 0.12 & 0.15 & 0.19 & 0.20 & 0.20 \\
\hline$\omega_{3}\left(\mathrm{~s}^{-1}\right)$ & 7.8 & 6.4 & 5.4 & 5.0 & 4.8 \\
\hline$S_{R}$ & & +1.13 & +1.30 & +1.32 & +1.34 \\
\hline
\end{tabular}

Table 1. CNLS fitting results of the system $\mathrm{TiO}_{2} / \mathrm{CNT}-\mathrm{WT} / \mathrm{TiO}_{2}$, relaxation times and sensor response. The positive value of $S_{R}$ is to indicate an increase in the resistance

response of titania grain boundaries, subcircuit 2 is the response of CNTs, and subcircuit 3 is related to the response of impurities in CNT-WT, these correlations are summarized in Table 3. The removal of impurities (i.e. elimination of the third subcircuit) and the decrement in $\mathrm{R}$ values reduce the relaxation times up to three orders of magnitude, from seconds for composites with CNT-WT to miliseconds for composites with CNT-2.5. Another benefit of the functionalization is that the capacitance response computed from equation 5 increases up to $\sim 2.5$ (i.e., $150 \%$, Table 2) in composites with CNT-2.5, which is about one order higher than the response of resistors [ 1.2, i.e., 20\%, Figure 11(a), Tables 1 and 2].

$$
\mathrm{S}_{\mathrm{C}}=\mathrm{C}_{\mathrm{ammonia}} / \mathrm{C}_{\mathrm{air}}
$$

\begin{tabular}{|c|c|c|c|c|c|}
\hline Element & Air & $1 \%, 5 \min$ & $4 \%, 5 \mathrm{~min}$ & $4 \%, 10 \mathrm{~min}$ & $4 \%, 15 \mathrm{~min}$ \\
\hline $\mathrm{R}_{0}(\Omega)$ & 26 & & & & \\
\hline $\mathrm{R}_{1}(\Omega)$ & 31 & & & & \\
\hline $\mathrm{C}_{1}(\mathrm{nF})$ & 44 & & & & \\
\hline $\mathrm{\tau}_{1}(\mu \mathrm{s})$ & 1.3 & & & & \\
\hline$\omega_{1}\left(\mathrm{~s}^{-1}\right) \times 10^{5}$ & 7.3 & & & & \\
\hline $\mathrm{R}_{2}(\Omega)$ & 168 & 219 & 220 & 222 & 222 \\
\hline $\mathrm{Q}_{2}{ }^{0}\left(\mu \mathrm{Ss}^{\mathrm{n} 2}\right)$ & 55 & 19 & 15 & 14 & 14 \\
\hline $\mathrm{n}_{2}$ & 0.6 & 0.7 & 0.8 & 0.8 & 0.8 \\
\hline $\mathrm{C}_{2}(\mu \mathrm{F})$ & 1.4 & 2.5 & 2.9 & 3.2 & 3.4 \\
\hline $\mathrm{T}_{2}(\mathrm{~ms})$ & 0.23 & 0.54 & 0.64 & 0.69 & 0.76 \\
\hline$\omega_{2}\left(\mathrm{~s}^{-1}\right) \times 10^{3}$ & 4.2 & 1.8 & 1.5 & 1.4 & 1.3 \\
\hline $\mathrm{S}_{\mathrm{R}}$ & & +1.106 & +1.097 & +1.104 & +1.112 \\
\hline
\end{tabular}

Table 2. CNLS fitting results of the system $\mathrm{TiO}_{2} / \mathrm{CNT}-2.5 / \mathrm{TiO}_{2}$, relaxation times and sensor response. The positive value of $S_{R}$ is to indicate an increase in the resistance 

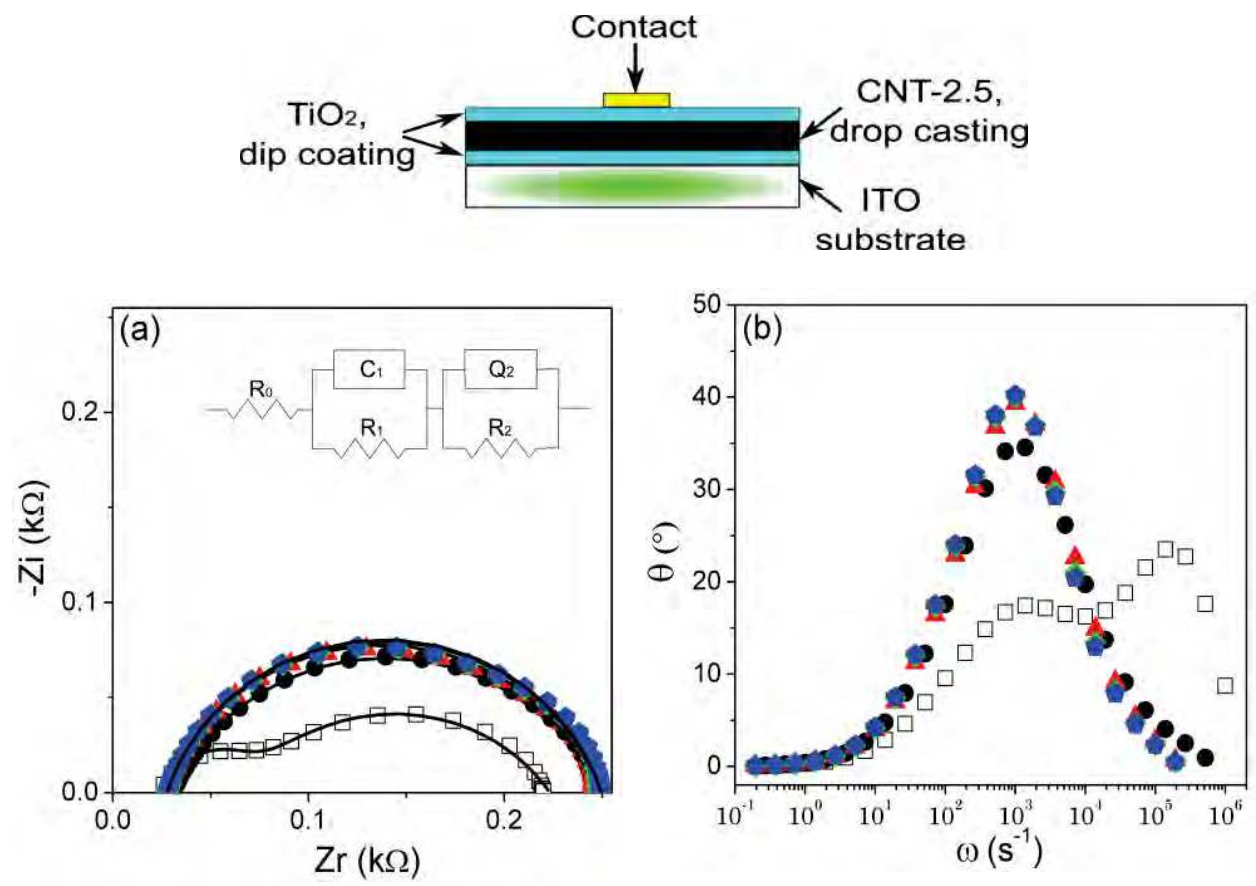

Fig. 14. EIS studies of $\mathrm{TiO}_{2} / \mathrm{CNT}-2.5 / \mathrm{TiO}_{2}$ composite with CNTs deposited by drop casting and $\mathrm{TiO}_{2}$ layers prepared by dip coating: (a) Cole-Cole plot; (b) phase angle vs. angular frequency. Colors code:white square: air; black circle: $\mathrm{NH}_{3} 1$ vol.\%; red triangle: $\mathrm{NH}_{3} 4$ vol. \%, 5 min; green diamond: $\mathrm{NH}_{3} 4$ vol. \%, 10 min; blue pentagon: $\mathrm{NH}_{3} 4$ vol. \%, 15 min. Markers are experimental data and lines are fitting results.

\begin{tabular}{|c|c|c|}
\hline CMP-WT & CMP-2.5 & Correlation \\
\hline $\mathrm{R}_{0}$ & $\mathrm{R}_{0}$ & Resistance due to external connectors \\
\hline $\mathrm{R}_{1} \mathrm{C}_{1}$ & $\mathrm{R}_{1} \mathrm{C}_{1}$ (only in air) & $\mathrm{TiO}_{2}$ grain boundaries \\
\hline $\mathrm{R}_{2} \mathrm{Q}_{2}$ & $\mathrm{R}_{2} \mathrm{Q}_{2}$ & Carbon nanotubes \\
\hline $\mathrm{R}_{3} \mathrm{C}_{3}$ & & Amorphous carbon and impurities \\
\hline
\end{tabular}

Table 3. Correlation of the equivalent circuits elements with the adsorption sites of the multilayered composites CMP-WT and CMP-2.5

\section{Conclusions and future directions}

Design of composite materials based on combinations of nanoparticled titanium dioxide and multiwalled carbon nanotubes, using small amounts of nanotubes for low cost room temperature ammonia sensors have been demonstrated. For sensor fabrication, ex situ synthesis of $\mathrm{TiO}_{2}$ and functionalization of CNTs were carried out separately and deposited 
in a multilayer configuration. Composites were tested as resistors and capacitors during ammonia sensing based on CNTs functionalization and number of titania layers. Results indicated that the use of titania layers in combination with the substantial chemical oxidation of CNT surface produced a better material with synergistic properties for sensing applications.

\section{Acknowledgment}

We acknowledge the felloship provided by the Consejo Nacional de Ciencia y Tecnología, CONACYT-México (M. Sánchez), we thank to M.L. Ramón García for the XRD analysis and to P. Altuzar Coello for TGA analysis.

\section{References}

Adu, C.K.W.; Sumanesekera, G.U.; Pradhan, B.K.; Romero, H.E. \& Eklund, P.C. (2001), Carbon nanotubes: a thermoelectric nano-nose, Chemical Physics Letters, Vol. 337, pp. 31-35.

An, G.; Ma, W.; Sun, Z.; Liu, Z.; Han, B.; Miao, S.; Miao, Z. \& Ding, K. (2007), Preparation of titania/carbon nanotube composites using supercritical ethanol and their photocatalytic activity for phenol degradation under visible light irradiation, Carbon, Vol. 45, pp. 1795-1801.

Brinker, C.J. \& Hurd, A.J. (1994), Fundamentals of sol-gel dip coating, Journal de Physique III, Vol. 4, pp. 1231-1242.

Cullity, B.D. (1978). Elements of X-Ray Diffraction, Addison-Wesley, Massachussets, USA.

Espinoza, E.H.; Ionescu, R.; Chambon, B.; Bedis, G.; Sotter, E.; Bittencourt, C.; Felten, A.; Pireaux, J.J.; Correig, X. \& Llobet, E. (2007), Hybrid metal oxide and multiwall carbon nanotube films for low temperature gas sensing, Sensors and Actuators B: Chemical, Vol. 127, pp. 137-142.

Hieu, N.V.; Duy N.V.; Huy, P.T.; Chien, N.D.; Thamilselvan, M. \& Yi, J. (2008), Mixed $\mathrm{SnO}_{2} / \mathrm{TiO}_{2}$ included with carbon nanotubes for gas-sensing application, Physica $E$, Vol. 41, pp. 258-263.

Jhi, S.H.; Louie, S.G. \& Cohen M.L. (2000), Electronic properties of oxidized carbon nanotubes, Physical Review Letters, Vol. 85, pp. 1710-1713.

Ong, K.G.; Zeng, K. \& Grimes C.A. (2002), A wireless, passive carbon nanotube-based gas sensor, IEEE Sensors Journal, Vol. 2, pp. 82-88.

Ou, Y.; Lin, J.; Fang, S. \& Liao, D. (2006), MWNT-TiO 2 : Ni composite catalyst: A new class of catalyst for photocatalytic $\mathrm{H}_{2}$ evolution from water under visible light illumination, Chemical Physics Letters, Vol. 429, pp. 199-203.

Peng, S. \& Cho, K. (2003), Ab initio studies of doped carbon nanotube sensors, Nano Letters, Vol. 11, pp. 57-60.

Sánchez, M. \& Rincón M.E. (2009), Sensor response of sol-gel multiwalled carbon nanotubes$\mathrm{TiO}_{2}$ composites deposited by screen-printing and dip-coating techniques, Sensors and Actuators B: Chemical, Vol. 140, pp. 17-23.

Sánchez, M.; Rincón M.E. \& Guirado-López R.A. (2009), Anomalous sensor response of $\mathrm{TiO}_{2}$ films: electrochemical impedance spectroscopy and ab initio studies, The Journal of Physical Chemistry C, Vol. 113, pp. 21635-21641. 
Song, H.; Qiu, X.; Li, F.; Zhu, W. \& Chen, L. (2007), Ethanol electro-oxidation on catalysts with $\mathrm{TiO}_{2}$ coated carbon nanotubes as support, Electrochemistry Communications, Vol. 9, pp. 1416-1421.

Stan, G. \& Cole, M.W. (1998), Hydrogen adsorption in nanotubes, Journal of Low Temperature Physics, Vol. 110, pp. 539-544.

Valentini, L.; Cantalini, C.; Armentano, I.; Kenny, J.M.; Lozzi, L. \& Santucci, S. (2004), Highly sensitive and selective sensors based on nanotubes thin films for molecular detection, Diamond and Related Materials, Vol. 13, pp. 1301-1305.

Varghese, O.K.; Kichambre, P.D.; Gong, D., Ong, K.G.; Dickey, E.C. \& Grimes, C.A. (2001), Gas sensing characteristics of multi-wall carbon nanotubes, Sensors and Actuators B: Chemical, Vol. 81, pp. 32-41.

Villalpando-Páez, F.; Romero, A.H.; Muñoz-Sandoval, E.; Martínez, L.M.; Terrones, H. \& Terrones, M. (2004), Fabrication of vapor and gas sensors using films of aligned $\mathrm{CN}_{\mathrm{x}}$ nanotubes, Chemical Physics Letters, Vol. 386, pp. 137-143.

Wang, W.; Serp, P.; Kalck, P. \& Faria, J.L. (2005), Photocatalytic degradation of phenol on MWNT and titania composite catalysts prepared by a modified sol-gel method, Applied Catalysis B, Vol. 56, pp. 305-312.

Williams, K.A. \& Eklund, P.C. (2000), Monte Carlo simulations of $\mathrm{H}_{2}$ physisorption in finitediameter carbon nanotube ropes, Chemical Physics Letters, Vol. 320, pp. 352-358.

$\mathrm{Yu}, \mathrm{H}$.; Quan X.; Chen, S. \& Zhao, H. (2007), $\mathrm{TiO}_{2}$-multiwalled carbon nanotube heterojunction arrays and their charge separation capability, The Journal of Physical Chemistry C, Vol. 111, pp. 12987-12991.

Zhao, J.; Buldum, A.; Han, J. \& Lu, J.P. (2002), Gas molecule adsorption in carbon nanotubes and nanotube bundles, Nanotechnology, Vol. 13, pp. 195-200. 


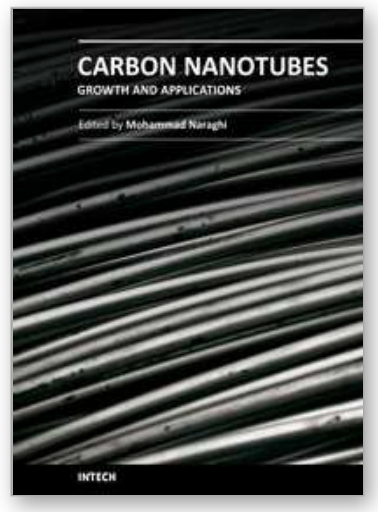

\section{Carbon Nanotubes - Growth and Applications}

Edited by Dr. Mohammad Naraghi

ISBN 978-953-307-566-2

Hard cover, 604 pages

Publisher InTech

Published online 09, August, 2011

Published in print edition August, 2011

Carbon Nanotubes are among the strongest, toughest, and most stiff materials found on earth. Moreover, they have remarkable electrical and thermal properties, which make them suitable for many applications including nanocomposites, electronics, and chemical detection devices. This book is the effort of many scientists and researchers all over the world to bring an anthology of recent developments in the field of nanotechnology and more specifically CNTs. In this book you will find:

- Recent developments in the growth of CNTs

- Methods to modify the surfaces of CNTs and decorate their surfaces for specific applications

- Applications of CNTs in biocomposites such as in orthopedic bone cement

- Application of CNTs as chemical sensors

- CNTs for fuelcells

- Health related issues when using CNTs

\section{How to reference}

In order to correctly reference this scholarly work, feel free to copy and paste the following:

Marciano Sánchez and Marina Rincón (2011). Ammonia Sensors Based on Composites of Carbon Nanotubes and Titanium Dioxide, Carbon Nanotubes - Growth and Applications, Dr. Mohammad Naraghi (Ed.), ISBN:

978-953-307-566-2, InTech, Available from: http://www.intechopen.com/books/carbon-nanotubes-growth-andapplications/ammonia-sensors-based-on-composites-of-carbon-nanotubes-and-titanium-dioxide

\section{INTECH}

open science | open minds

\section{InTech Europe}

University Campus STeP Ri

Slavka Krautzeka 83/A

51000 Rijeka, Croatia

Phone: +385 (51) 770447

Fax: +385 (51) 686166

www.intechopen.com

\section{InTech China}

Unit 405, Office Block, Hotel Equatorial Shanghai

No.65, Yan An Road (West), Shanghai, 200040, China

中国上海市延安西路65号上海国际贵都大饭店办公楼 405 单元

Phone: +86-21-62489820

Fax: +86-21-62489821 
(C) 2011 The Author(s). Licensee IntechOpen. This chapter is distributed under the terms of the Creative Commons Attribution-NonCommercialShareAlike-3.0 License, which permits use, distribution and reproduction for non-commercial purposes, provided the original is properly cited and derivative works building on this content are distributed under the same license. 